Article

\title{
Resentment and Coping With the Democratic Dilemma
}

\author{
Karen Celis ${ }^{1}$, Louise Knops ${ }^{1}$, Virginie Van Ingelgom ${ }^{2, *}$ and Soetkin Verhaegen ${ }^{3}$ \\ ${ }^{1}$ Department of Political Sciences, Vrije Universiteit Brussel, Belgium; E-Mails: karen.celis@vub.be (K.C.), \\ louise.knops@vub.be (L.K.) \\ ${ }^{2}$ Institute of Political Science Louvain-Europe (ISPOLE), UCLouvain, Belgium; E-Mail: virginie.vaningelgom@uclouvain.be \\ ${ }^{3}$ Faculty of Arts and Social Sciences, Maastricht University, The Netherlands; \\ E-Mail: s.verhaegen@maastrichtuniversity.nl \\ * Corresponding author
}

Submitted: 18 January 2021 | Accepted: 5 July 2021 | Published: 27 August 2021

\begin{abstract}
Resentment is a complex, multi-layered emotion, within which perceptions of unfairness and feelings of anger are central. When linked to politics, it has predominantly been associated with the alleged "crisis of representative democracy" and populism. However, recent studies have shown that resentment can intervene positively in people's relations to politics and political institutions by facilitating certain types of political participation (Capelos \& Demertzis, 2018). Despite this, the concept of resentment, and hence its role in contemporary representative democracy, is often poorly defined, with empirical investigations of its manifestation(s) remaining scarce. Borrowing a conceptualization of resentment as "resentful affectivity," our article draws on the analysis of focus groups carried out in Belgium (2019-2020) with individuals where resentful affectivity is likely to be observed (i.e., contemporary movements of contestation such as the Yellow Vests, Youth for Climate, and individuals who occupy a socially disadvantaged position). We find that experiences of intense anger, fear, disappointment, and the unfairness of representative democracy, i.e., of how representative democracy works on the ground, coexist simultaneously with remaining hopes in the democratic system. We show how this complex blend of emotions confronts citizens with what we call a "democratic dilemma." We document the different ways in which citizens cope with this dilemma and conclude by highlighting both the positive and negative ways in which resentment intervenes in the contemporary "crisis of representative democracy."
\end{abstract}

\section{Keywords}

affectivity; emotions; representative democracy; resentment

\section{Issue}

This article is part of the issue "Reactionary Politics and Resentful Affect in Populist Times" edited by Tereza Capelos (University of Birmingham, UK), Stavroula Chrona (King's College London, UK), Mikko Salmela (University of Helsinki, Finland / University of Copenhagen, Denmark), and Cristiano Bee (Oxford Brookes University, UK).

(C) 2021 by the authors; licensee Cogitatio (Lisbon, Portugal). This article is licensed under a Creative Commons Attribution 4.0 International License (CC BY).

\section{Introduction}

Recent decades have been marked by what is commonly described as a "crisis of representative democracy" (Crouch, 2004; Merkel et al., 2011; Tormey, 2014, 2015) to denote the increasing distrust, and defiance, that citizens express towards the institutions and actors of representative politics (see Droste, 2021, for a complementary analysis of feelings and beliefs among many citizens "left behind" and unheard by unresponsive polit- ical decision makers). Whether it is the rise of populist and anti-establishment actors, electoral abstention, political apathy, or political protest, citizens are finding various ways to express a sense of hate and disdain towards politics and established institutions (Hay, 2007). Arguably then, core systemic aspects of representative democracy find themselves on shaky ground when there is a decrease in political engagement, and withering trust in elected politicians. Drawing on the recent affective turn in the social sciences (Clough \& Halley, 
2007), the extant literature which focuses on the various deficits of electoral representation, populism, and anti-establishment politics, has increasingly paid attention to emotions (Cramer, 2016; Hay, 2007; Hochschild, 2016; Marcus, 2002; for an illustration of the role emotions play in citizens' political behaviours in the context of the Brexit vote, see Sullivan, 2021).

In this context, hate and disdain are often presented as intrinsic to citizens' troubled relationships with politics (Hay, 2007), and their feelings of being marginalized, undermined, and unrepresented are concomitantly found to be key explanatory factors in political events that mark our times, like the Brexit vote or the election of Trump (Akkerman et al., 2014; Bachman \& Sideway, 2016; Canovan, 1999; Cramer, 2016; Dodd et al., 2017; Hochschild, 2016; Kaltwasser \& Van Hauwaert, 2020; Spruyt et al., 2016). Resentment, the more complex affect capturing these emotions, is sometimes presented as the symptom and feature of the contemporary crisis of representative democracy (Fleury, 2020; Ure, 2015), of new forms of political "malaise" (Fukuyama, 2018; Hochschild, 2016), and the breeding ground for populism (e.g., Berlet, 2012; Hochschild, 2016). In contrast to this dominant understanding, or at least one strongly linked to it, other scholars point to resentment as engendering critical political engagement and thereby strengthening, invigorating, and innovating representative democracy (Capelos \& Demertzis, 2018; Norris, 2011).

Despite the somewhat ambivalent and important role that resentment plays in the contemporary democracy, the concept is seldom defined with clarity. Equally, empirical investigations remain both scarce and partial; something which is largely explained by the lack of data and the marked proclivity to focus on its link with populism and/or "unconventional" political action (Capelos \& Demertzis, 2018). Indeed, while the studies above hint at the role of resentment within different dimensions of the crisis of representative democracy, developing a more in-depth analysis of the nature and consequences of resentment is likely to generate more nuanced understanding. In this context, we investigate how different groups of citizens express resentment, and how this relates to their expectations of, and beliefs in, representative democracy. We conceive of resentment as "resentful affectivity" (Capelos \& Demertzis, 2018) and use it as a heuristic tool to empirically investigate how citizens express resentment, and more specifically, what emotions underlie these expressions of resentment towards representative democracy. Our empirical analysis is based on focus groups carried out in Belgium between 2019 and 2020, amongst populations where resentful affectivity might be considered high. This included contemporary movements of contestation such as the Yellow Vests and Youth for Climate, as well as those individuals who are in socially disadvantaged positions.

Our analysis of the focus groups reveals a complex amalgam of anger, fear, feelings of unfairness, disappointment, and hope, that commingle in a complex resentful affectivity towards representative democracy. In addition, we distinguish between the specific objects of these emotions. More precisely, we show what aspects of democracy resentful citizens are angry or disappointed about, what they fear, judge to be unfair, and in contrast, what they are hopeful about and feel empowered by.

\section{Resentful Affectivity and the Crisis of Representative Democracy}

Resentment is broadly defined as a feeling of "anger about a situation you think is unfair" (Resentment, n.d.). It denotes a particular type of anger that emerges in a context where one feels unfairly treated, for example, in comparison to others in society; a feeling that neighbours, say, are happier, more successful, wealthier, in ways classically understood as relative deprivation (Spruyt et al., 2016). In scholarly accounts, this definition is additionally layered with the idea of a "brewing anger" that accumulates over time, and displays a distinctively bitter connotation (see Fleury, 2020).

In this context, scholars have also relied on the semantic difference between resentment (the English word) and the French word ressentiment (used as such in English) to distinguish between two types of brewing anger that produce different types of attitudes (see, e.g., Salmela \& Capelos, 2021, for an in-depth theoretical discussion of resentment and ressentiment). Drawing on the foundational work of Scheler (1912), contemporary scholars (e.g., Capelos \& Demertzis, 2018) have relied on this distinction in the context of populism. They have associated "resentment" with a form of moral anger accompanied by a sense of self-efficacy that might act as a driver for engagement and action. In contrast, ressentiment is seen here as "a compensatory emotion of the powerless that expedites transvaluation so that the person can stand and handle his or her frustration" (Capelos \& Demertzis, 2018, p. 3). This semantic distinction points to the fact that the same moral anger may lead to different levels and/or kinds of political engagement.

More importantly, the main contribution of Capelos and Demertzis (2018) is the use of "resentful affectivity" as a concept that denotes both the complexity, and the fluidity, of emotions revolving in and around resentment. Here, they highlight various links between resentment and anxiety, fear, despair as well as varying levels of hope that intervene in the driving of political behaviour and attitudes. Their concept of resentful affectivity is especially useful when mapping the complexity of resentment and allows for the possibility of different effects that come from different constellations of resentful affectivity. This, in turn, opens the possibility of investigating and theorizing not only the negative, but also the positive impact of resentment on representative democracy. Their understanding of resentful affectivity includes "passive" and "active" forms of resentment, such as 
those usually defined as indignation (i.e., the mobilizing form of anger which triggers protest; e.g., Jasper, 2014). In these ways, resentment can result in increased political engagement (Capelos \& Demertzis, 2018) and, hence, can have potentially beneficial effects for democratic vitality. Or, put another way, resentment may indeed be linked with a crisis of representative democracy as many studies show, but it may also be a part of the dynamics that strengthen, invigorate, or innovate representative democracy by questioning and challenging it.

Resentful affectivity can also be used to distinguish between the different objects of various emotions. Anger and fear as the constitutive components of a resentful affectivity can, for instance, have a different object than feelings of hope which are constitutive of the same affectivity. This unlocks the possibility to see and understand different affective responses to different dimensions and forms of democracy, and, by doing so, improve our understanding of resentment's relation to the current crisis of representative democracy. This requires expanding the analytical scope of resentful affectivity beyond the negative consequences of resentment, and in particular, beyond its relation to populist voting.

\section{Methods}

Two analytical questions lead our research to deepen the understanding of resentment-defined by Capelos and Demertzis (2018) as discussed in the previous sectionand its relationship with attitudes and expectations about representative democracy: (1) What affects and emotions characterize citizens' resentment towards politics (understood here as the practices, actors, and institutions of representative democracy)? And (2) How does resentment towards representative democracy relate to beliefs and expectations about democracy more broadly? This section explains how an abductive method, analysing focus group discussions, gives answers to these questions.

\subsection{Data: Focus Groups}

Analysing focus group discussions makes it possible to unravel the complex relationships citizens have with representative democracy by allowing them to express and confront their views on politics through agreement and disagreement (Duchesne, 2017; Morgan, 2010; Van Ingelgom, 2020). The focus group data used in this article were collected between April 2019 and February 2020 in the framework of the EOS RepResent project (FNRS-FWO no. G0F0218N) that examined the relationship between democratic resentment and political representation in Belgium. For this purpose, focus groups were organized with members of populations where resentful affect might be expected: contemporary movements of contestation, as well as socially disadvantaged individuals (Capelos \& Demertzis, 2018; Feather, 2015). For the purposes of this article, we focus on the discussions that took place in four focus groups (19 participants in total) carried out in the Brussels region: one focus group with participants in the Yellow Vests protest, one with participants of Youth for Climate, one with inhabitants of Molenbeek (one of Brussels' least advantaged areas adjacent to one of the city's most advantaged areas), and one with blue-collar workers in the European Parliament (for an analysis of how low- and middle-income populations are more vulnerable to economic distress, which can increase their resentment toward democracy, see Ferrari, 2021). The selection of participants thus captured a diverse sample of citizens where resentful feelings were expected (given active involvement in social movements or given one's social position), and allowed us to inquire into the variant and diverse ways citizens express resentful affectivity. The Supplementary File 1 provides background information on the participants, illustrating the heterogeneity of their socio-demographic profiles. The sampling was theoretically driven, but did not necessarily aim for saturation; instead, comparison was key, and the sampling relies more on the principle of diversity (Van Ingelgom, 2020). Sampling data based on diversity, rather than on saturation or generalizing findings to a larger population, was instrumental in gaining the theoretical traction essential for this type of analysis.

In excavating citizens' feelings of resentment and views on (representative) democracy, each focus group was organized around three guiding questions proven to be relevant to study citizens' relationships towards politics (White, 2010). The focus groups opened with the questions: (1) What are the most important societal challenges that Belgium is facing today? (2) Who should take care of those issues? And (3) How should they be resolved (i.e., political solutions)? The average length of the focus groups was 2.5 hours. All focus groups were audio recorded-and when participants agreed (written informed consent was required for participation)filmed. Based on these recordings, anonymized verbatim transcripts were made. The focus groups took place in French or Dutch, and the excerpts of the transcripts are translations by the authors. The Supplementary File 2 presents the four focus groups in more detail.

\subsection{Analysis: An Abductive Approach}

As with other contemporary social scientists interested in theory-building, our qualitative analysis favours shared standards of cumulative theory building (Lamont \& White, 2009) and follows an abductive approach. Abduction as a method of data analysis was initially developed by Peirce (1934) as a way to draw inferences that are oriented towards theory-building. As such, abduction is distinct both from deductive and inductive methods, but combines features of both types of inferences. Building on abductive analysis principles, our results consider relevant insights from previous studies in the literature (Tavory \& Timmermans, 2014; 
Timmermans \& Tavory, 2012). We develop abductive inferences through in-depth interpretive analysis following a two-step approach: first, analysing focus groups one by one in order to understand and characterize resentment and prevalent beliefs in, and expectations of, representative democracy in the light of previous studies; then, comparing the findings by looking for anomalies inside and between focus groups. In this way, qualitative data analysis consists of analysing and comparing transcripts iteratively, while also being sensitive to theoretical insights (Tavory \& Timmermans, 2014; Timmermans \& Tavory, 2012). We build on the scholarship around resentful affectivity by improving the conceptual clarity about the meaning and boundaries of resentment. This not only leads to a more nuanced understanding of contemporary forms of resentment, but also greater analytical clarity regarding the various ways resentment links to citizens' beliefs in, and expectations of, representative democracy.

\section{Findings}

Our analysis shows different variations of resentful affectivity towards representative democracy. Participants' expressions of resentment were grounded in a combination of contradictory emotions: anger, fear, disgust, desperation, and unfairness, but also hope, feelings of empowerment, and enthusiasm. This affectivity is expressed in relation to a profound dissatisfaction with the way "representative democracy works," but not a wholesale rejection of democracy as a principle, or as an ideal to attain. Strikingly, some participants expressed resentment towards representative democracy, while at the same time remained hopeful that the same set of institutions will bring solutions. In the remainder of this article, we refer to this tension as a "democratic dilemma." In particular, our analysis documents different ways in which participants cope with this democratic dilemma: the tension between disillusion in democratic institutions and their remaining hopes. In some cases, participants explained that they reverted to voting blank in elections, or resorted to protest and advocated democratic alternatives. Elsewhere, participants still shared the belief that the current system has the potential to function well. Below, we present our findings in detail. In Section 4.1, we unpack the interplay between anger, fear, unfairness, and disappointment which underlies the resentful affectivity as observed in our data. In Section 4.2, we examine how these are related to more positive emotions such as hope, and in Section 5, we discuss the different ways of coping the participants deployed in the face of this "democratic dilemma."

\subsection{Resentful Affectivity: Anger, Fear, Unfairness, Disappointment}

In the accounts of participants, and in line with the existing literature, resentment is connected to anger, and especially a "brewing anger" that accumulates over time, displaying a distinctively bitter connotation, and often connected to disappointment. Those elements emerged clearly in the analysis of participant's exchanges in Molenbeek - a group composed of individuals who are in a socially disadvantaged position. The participants in this group expressed very explicit resentment towards politics, and some connected this to voting "blank" in the last elections as a protest against politicians failing to listen to them, and as an expression of disbelief in what politicians say. Interestingly, they explained or even justified-morally-their resentment, as a logical reaction to the distance and remoteness of politicians outside of election periods. In this group, we observed that resentment went hand in hand with the rejection of (elements of) the political system and political elites. In the following quotes, Mehmet expressed this rejection with a lot of anger: He starkly articulated his feeling of being ignored by political representatives as well as civil servants (in this quote, the municipality), as comparing "us" to dogs and even shit. Moreover, his bad experience when turning to the municipality services for help illustrates disappointment and the anger this raised:

Abbou: There is no longer contact between inhabitants and politicians. It's a bit normal that we're going to vote blank.

Mehmet (interrupting): There are many blank votes, yes, yes.

Abbou: Well, it's normal [to vote blank] because we no longer believe what politicians say. I don't believe them anymore. I've been voting blank for several years now.

Adil (interrupting): Politicians should come to the field, bring people together and talk.

Abbou (interrupting): There, I agree too, of course.

Adil (continuing): I think this is the best idea.

Mehmet: And even I will pass by then, in contrast to the municipality [of Molenbeek].

\section{Moderator: Yes.}

Mehmet: Uh, they talk too badly. When I had a problem, I dropped by with my brother-in-law...."No, you didn't pay for that, you didn't pay for that." She [the civil servant of the municipality] treated us like dogs. I mean, sorry for that term, she spoke to us like, like we were shit, actually.

This illustrated an explicit form of resentment towards politics that goes to the heart of the relationship between voters and representatives in representative 
democracy. The participants of this group from Molenbeek reached a broad consensus around not being listened to by politicians (Noordzij et al., 2020) and not trusting what they say. Perhaps more importantly, this was not a one-off experience, but rather a repetitive and long-lasting source of frustration.

This feeling of not being listened to is shared by many participants in the different groups, yet we observed variation in how resentment is expressed. Beyond the angry slogans of the climate marches, the exchanges among the Youth for Climate participants reflected a genuine anger. Their anger was directed at many different targets but was particularly explicit when they denounced the inaction of political elites in the face of climate change. Their critique of politics echoes broader societal concerns about the flaws of "career-politicians" and democratic myopia; the incompatibility of short-term electoral cycles with the necessary long-term vision inherent to address climate change.

However, in this case, we did not observe the same kind of frustration that accumulates over time. This may be linked to the age of the young activists, but also to the context in which their anger is expressed: a moment of intense mobilization. As explained by Knops (2021), this more active form of resentment, often called "indignation" (Jasper, 2014) is what characterizes their affective repertoire. As their conversation proceeded, their anger was marked by a kind of impatience (demanding that politicians act now!), and a form of disdain; "looking down" on politicians:

Arthur: I mean, if a politician could not run for another term, if he had only four years to do exactly what he wanted, without thinking of the next onenot thinking about pleasing people-he would focus on the ideas he wants to implement. Because, as we know, politicians just spend time taking care of their image, and making sure they remain popular.

Arthur: They are really losing time... losing a lot of time.

Loic: Yeah, and actually, I used to think "ok, five years is a good amount of time to do something," but now when I think of the climate and I think that, if we carry on, we might enter an ice-age in 2040, it's just not enough!

In the focus group with Yellow Vests activists, fear was a central affect; and fear, as we have discussed above, is also part of resentful affectivities. When asked to describe what they saw as key problems in society, the Yellow Vests participants pointed toward a deep-rooted fear of falling further into precarity, the impact of climate change, an unhealthy environment, and unemployment. The participants also discussed how politicians try to use this fear to convince people of their own politics and to "keep the people down," describing politics as "a gigantic monster":
Otto: According to me, the biggest problem is poverty. And thus, the fear for poverty linked to unemployment. I believe that that is the biggest problem.

Otto: A big fear. A big fear. That is a big problem, and that fear... you cannot simply say "come on, do a therapy session." No, no it has nothing to do with that. If there is no security, then people do strange things.

Daan: Fear is a strong motive for people.

Otto: So, the fear of being poor. Fear that soon our bees are no longer able to fertilize our fruit. Fear that our children... yeah, can no longer live in a healthy environment. Fear, fear, fear.

Besides the feelings of brewing anger, frustration, and fear, all the focus groups reflected feelings of unfairness in relation to participants' resentment towards representative democracy. An illustration of this can be found in the focus groups with blue-collar workers in the European Parliament, particularly when participants discussed inequalities. One inequality they observed was between people like them and "political and economic elites":

Cathie: I think that if they [politicians] would lower their salaries, and would learn to live with the wages that we are paid every month, I believe that they wouldn't manage. It would also be good that, instead of always coming up with all their blah blah blah, if they would learn to live like us, with the same monthly budget, we would see whether they still come up with the same proposals.

These types of sentiment echo previous findings on cultural distance between citizens and elites (Noordzij et al., 2020). Here, the participants felt a distinct disconnect, a sense of distance from elites who rarely understood their situation and do not try to improve it. In the conversation, this inequality was framed within the experience of a systemic hierarchy. It was observed at the workplace, where people working for the European Parliament have more rights and better living conditions than people working for subcontractors. At various points in the discussion, the experience of being at the bottom was discussed along with the frustration of voicelessness and not being heard. In these discussions, a sense of powerlessness is also perceptible. In the Molenbeek focus group, participants also expressed resentment by sharing their personal stories, and the experiences of unfairness and injustice they had lived through. This use of personal experiences with unfairness and injustice is very explicit in Mehmet and Abbou's conversation. Mehmet draws on his encounter with civil servants at the Molenbeek municipality services, while the other participants join the exchange with their personal experiences of getting "their papers" (residence permits) in 
order. Here, they contrasted the poor experiences of "non-Belgians" with the more positive service received by Belgian citizens. For these participants, sharing their experiences was the key to justifying their expressed resentment, and demonstrating how "normal" it is for them to feel the way they do towards politics, and justify their actions (e.g., voting blank).

This section has illustrated the interplay between the brewing anger, the long-lasting frustration, disappointment, and the experiences of unfairness which underlie participants' resentment towards politics, understood here as actors and institutions of representative democracy. We have also highlighted the important role played by fear and the mobilization of anger, and the indignation felt by some of our analysed groups. Some participants used these feelings to explain why they vote blank, others explained that this led them to participate in protests. Section 4.2 shows how these feelings are also linked to remaining hopeful and having trust in existing political institutions.

\subsection{But Also Hope, Enthusiasm, and Trust Towards (Representative) Democracy}

In contrast to the emotions described in Section 4.1, in various instances participants' resentment is linked to emotions such as hope. This is expressed towards the representative system and made space for ideas on how to improve the existing system, rather than abolishing it entirely. These ideas typically implied increased citizen input and greater dialogue with their representatives. In their own words, participants expressed hope that there was a solution to the current situation. For example, the participants of the Molenbeek group discussed how the mayor should consult citizens; she should come to the field (as the researcher recruiting them did):

\begin{abstract}
Abbou: It was the mayor Françoise Schepmans who destroyed it [a parking lot]? Well she should have first consulted with all the locals who live there before she decided, you see?
\end{abstract}

Walid: Yeah.

Abbou: And she did it on her own, you see? Maybe I don't know with whom she consulted, why she didn't come on the field, why like Mr [pointing to the moderator who did the recruitment] came towards us anyway. Still he dared to ring our doorbell. That's why we're here today. See? But she didn't. She didn't come to the locals, she didn't speak.

This quote is highly illustrative of the tension between anger or frustration, and hope and faith in representative democracy. Indeed, Abbou's resentment towards politics does not lead him to promote solutions outside the current political system. Elected representatives should, and can, establish better representative relationships. When, in the previous quote, he strongly stated: “I couldn't give my vote to those politicians who don't have... who don't keep their word," he is, in fact, displaying that he values representative democracy and his own vote. He does not trust politicians, but he still, implicitly, values the institution of voting. In the same vein, Abbou says that "we don't believe politicians anymore," but he also implies that if politicians were willing to listen, citizens would show up to share their opinions when consulted. Abbou's dilemma perfectly illustrates how resentful individuals often have contradictory expectations of the institutions of representative democracy, which go beyond a surface antagonism with "the establishment." As the next quote illustrates, however disappointing the institutions of representative democracy are, they do remain part of the solutions envisaged for the future:

Mehmet: Well, I think it's the state that has to, to move, you see. I don't know, or either it's the municipality that is, if it's the municipality actually that runs everything, uh, the city, I think they should be reacting at the same time too.

Adil: I think that the, the mayor, he must also-as you are doing there [referring to the researchers] - bring people together from time to time and talk about neighbourhood problems, about... citizens who live in the region. They find solutions, I'm not saying right away, but as we go, uh, we solve one problem today, some, sometime after we solve another, and then voilà. But it's, it's, we come back to it, if he's not in the field, he's never going to understand people's problems.

This tension between anger and hope when discussing electoral politics was also found in the other groups. The European Parliament blue-collar workers, for example, expressed being fed up with the system and pointed out that politicians only tell nice stories during elections, but otherwise they do not care. However, hope was expressed when participants discussed voting, politicians, and political parties with the comment that: "Some politicians do have a heart....One has to keep hoping, each time there is elections." Similarly, as the quote below shows, despite their strong critique of political representatives, Youth for Climate participants reflected a high level of trust and hope in the same institutions they critiqued:

Amelie: For me it [the solution] must come from politics, it is the political world that at some point should say: "Ok, with our expertise as ministers we are not able to find a solution," but instead we will invest more heavily in climate research, we will hire a team of scientists, trust them, and let them bring the solutions.

Indeed, at the time of the focus group, the Youth for Climate participants still expressed hope in the electoral 
system in general, with participants strongly supporting, for example, the institution of voting (saying that it "is the basis of democracy"). Their hope is not blind or naive, however. Participants showed awareness of the complexity of decision-making and climate change politics. In this quote, we argue that they are not expressing a preference for expert governments, but rather, for elected representatives to acknowledge the limits of their expertise and to ask for more expert assistance when developing policy.

The Yellow Vests participants' outspoken ideas about how the political system needs to change take a different direction. They hold no more hope in electoral politics but remain committed to the ideals of democracy. In this context, participants called for radical democratic reform, in particular through the introduction of referenda. Indeed, the electoral, representative dimension of the current democratic system, and especially the institution of "political parties," is described in very negative terms, whilst referenda and citizen assemblies are seen as the way to re-locate democratic power within the hands of "the people" itself. They used their concrete experiences of engagement with the Yellow Vests, organizing assemblies and meetings amongst people with very different ideological preferences, for example, to illustrate the importance of deliberation between people with different views, and their distinction from political parties, which "in the end will always choose the party above the people." This distrust in the representative function of political parties led them to vote for small counter-parties as an expression of their discontent with mainstream politics. Hence, they too, whilst critical of many facets of representative democracy, nonetheless put their hopes into more direct forms of democracy.

Overall, the Yellow Vests participants painted a very grim picture of society and politics, yet they were excited and hopeful that their actions had the potential to bring positive change. What is happening in the Yellow Vests movement was described as "brilliant," a "growing positive vibe," that "they are doing well" and were "on the winning side." The Yellow Vests participants felt empowered and believed that the table had turned, with politicians now the ones who were afraid:

Daan: This is a piece of clothing [referring to the yellow vest]. The very fact that the government takes away a piece of clothing, that is indeed that fear. It means that fear has changed sides, and that this small gadget [waves with the yellow vest], that should be in your car, that I wear at work, that it becomes a symbol, and that they fear that symbol.

Daan: Yes, literally fear and that politics is aware of this gigantic weapon.

Lara: We started very sweet with the yellow vests. What is it? It says: Fear, fear, fear. Just a thing. Putting on a vest to say: Fear. We cannot take it any longer. It is starting to explode.

This section illustrated how the tension between simultaneous assertions of resentment towards politics and hope in the power and agency of citizens in representative democracy, and democracy more generally, was a tangible feature of the findings. This informed us of the various ways in which citizens "cope" with the democratic dilemma, which we discuss in greater detail in Section 5.

\section{Coping With the "Democratic Dilemma"}

Our analysis sheds light on the resentful affectivity expressed by participants, and how it relates to representative democracy and alternatives (including elections, politicians, policy-making, and policy implementation). Our findings also show how resentments toward institutions of representative democracy are more accurately described as ones which encompass hope, with regard to various aspects of the overall democratic system. This simultaneous experience of strong negative feelings towards representative democracy in Belgium, alongside the hope that solutions lie in key democratic ideals and practices of the very same system, confronts citizens with what we call a "democratic dilemma." The analysis shows that this mix of positive and negative emotions elicits different responses in the way individuals act, as a means of coping with their democratic dilemma. This reflects the presence of variant beliefs and expectations towards and beyond representative democracy.

Some participants coped with this dilemma by voicing their discontent with the existing electoral system. Some did this by voting for parties regarded as offering an alternative to "mainstream" politics, by, for example, voting for populist parties, or (small) counter-parties. Yet, participants were also hopeful that politicians who understood and wanted to represent the interests of people "like them" could still emerge and step forward. In other words, whilst some participants concluded that the system did not serve them well, they did not necessarily blame representative democracy per se. Rather, they blamed individual political representatives who are currently in power, or a particular way of doing politics (distant, campaign-oriented, and "not listening to us"). For this reason, some participants expressed the importance of not giving up and keep hoping for a better outcome at the next electoral round. Other participants, in contrast, expressed their resentment towards electoral institutions specifically and voted blank. To justify this form of withdrawal, individuals blamed political elites and the disappointing options they get in elections. Yet, voting blank shows that they did not reject the principle and institution of voting per se. In this sense, voting blank became a way of temporarily coping with their chronic disillusionment with politics, and a way of drawing attention to both their dissatisfaction and dysfunction of electoral democracy. 
Elsewhere, participants engaged in radically different types of action, including participating in (or organizing) protests. Here too, hope is partially vested in existing institutions, with politicians becoming the target audience of these protests. They are urged to improve policies, for instance, by acting more efficiently and effectively on climate change, or by taking the lived experiences of "average citizens" into account with greater integrity. Similarly, in the Youth for Climate groups, we saw that those politicians who were blamed for insufficient action were paradoxically perceived to be the same actors who hold the power to take meaningful decisions and go beyond the short-term thinking imposed by elections. Participants are thus hopeful about the power of mobilization to bring politicians to this realization.

Both Youth for Climate participants and Yellow Vests participants nonetheless linked this type of action to democratic alternatives. In the Youth for Climate discussions, it was explained that politicians lacked the necessary expertise to make good policy and should involve more experts. The Yellow Vests stressed that citizens should be the main locus of power in democracy, hence their proposal to strengthen this role with citizen deliberations and referenda. Participants' belief in the viability of these alternatives was commonly based on examples from abroad or neighbouring movements, and on their own practice of democratic deliberations, as was the case with the Yellow Vests movement.

Finally, our findings strongly suggest that total inaction and disengagement was not part of the coping strategies resentful citizens developed in relation to politics (at least not within the groups that we have analysed). This does not mean that resentful affectivity never leads to such inaction, or put differently, that resentment cannot unchain ressentiment, i.e., resentful victimhood, inaction, and powerlessness. Nevertheless, it is still noteworthy that it was not observed in our discussions with participants who came from radically different backgrounds.

The resentful affectivity and the democratic dilemma that we identified in our data pave the way to a clearer understanding of how resentful citizens deal with the democratic dilemmas they face: by voting for politicians and parties believed to offer an alternative to the politicians that do not listen to them, by voting blank, by protesting, or by vesting hope in alternatives to complement the current system of representative democracy.

\section{Conclusions}

This article draws on theoretical and empirical insights to clarify the links between resentment, and views and expectations toward democracy. We analysed four focus groups with citizens from various socio-economic backgrounds, including activists involved in social movements, as well as individuals from socially disadvantaged positions. We unpacked their resentment towards politics and how they cope with it, to show, significantly, that resentful affectivity is expressed in various ways. We observed varying combinations of, on the one hand, anger, fear, frustration, disappointment, feelings of unfairness, and indignation, yet on the other, various forms of hope and trust. At the same time, there was a striking commonality across these highly varying groups, that the aspect of politics most closely associated with the anger, frustration, disappointment, and feelings of unfairness was the strong feeling that politicians do not listen to citizens like them. This issue is at the heart of how representative relationships should work and at the heart of the contemporary crisis of representative democracy.

Our analysis demonstrates a simultaneous experience of these strong feelings of anger, fear, disappointment, and unfairness about representative democracy, and more precisely, how (electoral) representative democracy works on the ground, and the hope vested in the (representative) democratic system. Rather than studying the effects of single emotions, it is only by embracing this complexity of emotions, captured in our study by using resentful affectivity as a heuristic tool, that resentment shows it potential as a political force. This complex emotional blend of resentful affectivity confronts citizens with what we have called a "democratic dilemma." We observed the different ways this dilemma was coped with: Some expressed continued hope in electoral representation and that it can and should be improved; others judged it to be beyond salvation and put their hope in more participatory and direct democratic solutions. Despite being passionately criticized, and rejected, by many of the resentful citizens included in our study, not all participants had lost hope in representative democracy. For example, some voted for politicians and parties which they believed to offer an alternative to the politicians "who do not listen to us," whilst others voted blank, or turned to protesting. Moreover, the commonality across the groups analysed was that, despite showing an explicit resentment towards political elites, and elites in general, all stayed within the boundaries of what would be considered democratic values and ideals, be it an improved representative democracy or a shift to another form of democracy (for example, direct democracy). However, we also observed that citizens do not always turn to ideas about improving the democratic system to cope with the "democratic dilemma" they face. Coping solutions are also found at the personal level, like exhortations to "taking one's own responsibility," or through collective engagement, by connecting with fellow citizens through mobilization.

Whether or not the expressions of resentment we found in our study undermine or strengthen democracy over the medium to long term, is an empirical question we do not answer. The salient finding, however, is that none of the resentful citizens included in our study rejected democracy per se, and many remained hopeful about democracy (albeit not always in its representative form). This finding, in turn, challenges 
the often-implicit claim that resentment is mostly detrimental for democracy.

Our findings suggest two potential avenues for future research about resentment: how it plays out in political attitudes and behaviour over time, and further specifying and delineating its relationship to the health of democracy in particular. Our study only began to explore these questions. First, the conversation between extant scholarship and our own empirical analysis on resentment sheds light on the ways in which our understanding of the nature and the political effects of resentment can be strengthened. Our study is based on a snapshot of the emotions at play at a certain moment in time, and is, in that respect, static. However, emotions are continually evolving, and such a dynamic should therefore be accounted for. We can, for instance, imagine that when hope and trust prove to be empty and evaporate over time, resentment will impact political attitudes and behaviour differently. Indeed, rather than resentment as such, it might be precisely such a shift "within" resentful affectivity that drives citizens away from democratic politics - the tipping point, if you will, when resentment becomes ressentiment. Secondly, our findings show that understanding the affective dimension of populism is not only key, but can also be greatly improved by establishing a more systematic understanding of which kind of resentful affectivity-i.e., which mix and balance of emotions-undermines democratic attitudes and behaviour. Obviously, political contexts such as anti-democratic leadership and discourses, and (material and non-material) resources of resentful citizens should also be considered. Such context-specific variables and group-specific features might mediate how the democratic dilemma is solved, and, more significantly, impact upon the relationship between types of resentful affectivity and citizens' attitudes within and beyond democratic boundaries.

\section{Acknowledgments}

This research was supported by the FNRS-FWO funding no. G0F0218N (2018-2021), FWO grant no. G062917N (2017-2021), and the VUB Strategic Research Programme Evaluating Democratic Governance in Europe (EDGE, 2018-2022). The authors thank all colleagues involved in the data-gathering: Kenza Amara-Hammou, Louise Knops, Guillaume Petit, François Randour, Ramon van der Does, Soetkin Verhaegen, Karen Celis, Kris Deschouwer, Benoît Rihoux, and Virginie Van Ingelgom.

\section{Conflict of Interests}

The authors declare no conflict of interests.

\section{Supplementary Material}

Supplementary material for this article is available online in the format provided by the author (unedited).

\section{References}

Akkerman, A., Mudde, C., \& Zaslove, A. (2014). How populist are the people? Measuring populist attitudes in voters. Comparative Political Studies, 47(9), 1324-1353.

Bachman, V., \& Sideway, J. (2016). Brexit geopolitics. Geoforum, 77, 47-50.

Berlet, C. (2012). Reframing populist resentments in the Tea Party movement. In L. Rosenthal \& C. Trost (Eds.), Steep: The precipitous rise of the Tea Party (pp. 47-66). University of California Press.

Canovan, M. (1999). Trust the people! Populism and the two faces of democracy. Political Studies, 47, 2-16.

Capelos, T., \& Demertzis, N. (2018). Political action and resentful affectivity in critical times. Humanity \& Society, 42(4), 1-24.

Clough, P., \& Halley, J. (2007). The affective turn: Theorising the social. Duke University Press.

Cramer, K. J. (2016). The politics of resentment: Rural consciousness in Wisconsin and the rise of Scott Walker. The University of Chicago Press.

Crouch, C. (2004). Post-democracy. Polity.

Dodd, N., Lamont, M., \& Savage, M. (2017). Introduction to BJS special issue. British Journal of Sociology, 68(S1), S3-S10.

Droste, L. (2021). Feeling left behind by political decisionmakers: Anti-establishment sentiment in contemporary democracies. Politics and Governance, 9(3), 288-300.

Duchesne, S. (2017). Using focus groups to study the process of (de)politicization. In S. Barbour \& D. L. Morgan (Eds.), A new era in focus group research (pp. 365-387). Palgrave Macmillan.

Feather, N. T. (2015). Analyzing relative deprivation in relation to deservingness, entitlement and resentment. Social Justice Research, 28, 7-26.

Ferrari, D. (2021). Perceptions, resentment, economic distress, and support for right-wing populist parties in Europe. Politics and Governance, 9(3), 274-287.

Fleury, C. (2020). Ci-gît l'amer: Guérir du ressentiment [Here lies the bitter: To heal resentment]. Editions Gallimard.

Fukuyama, F. (2018). Identity: The demand for dignity and the politics of resentment. Farrar, Stras \& Giroux.

Hay, C. (2007). Why we hate politics. Polity Press.

Hochschild, A. R. (2016). Strangers in their own land: Anger and mourning on the American right. The New Press.

Jasper, J. M. (2014). Constructing indignation: Anger dynamics in protest movements. Emotion Review, 6(3), 208-213.

Kaltwasser, C. R., \& Van Hauwaert, S. (2020). The populist citizen: Empirical evidence from Europe and Latin America. European Political Science Review, 12, 1-18.

Knops, L. (2021). Stuck between the modern and the terrestrial: The indignation of the Youth for Climate movement. Political Research Exchange, 3(1). 
https://doi.org/10.1080/2474736X.2020.1868946

Lamont, M., \& White, P. (2009). Workshop on interdisciplinary standards for systematic qualitative research (final report). National Science Foundation.

Marcus, G. E. (2002). The sentimental citizen: Emotion in democratic politics. The Pennsylvania State University Press.

Merkel, W., Fotou, M., Alonso, S., \& Kean, J. (Eds.). (2011). The future of representative democracy. Cambridge University Press.

Morgan, D. L. (2010). Reconsidering the role of interaction in analyzing and reporting focus groups. Qualitative Health Research, 20(5), 718-722.

Noordzij, K., de Koster, W., \& van der Waal, J. (2020). "They don't know what it's like to be at the bottom": Exploring the role of perceived cultural distance in less-educated citizens' discontent with politicians. British Journal of Sociology, 72(3), 566-579.

Norris, P. (2011). Democratic deficit: Critical citizens revisited. Cambridge University Press.

Peirce, C. (1934). Collected papers of Charles Sanders Peirce. In C. Hartshorne \& P. Weiss (Eds.), Pragmatism and pragmaticism (Vol. 5). Harvard University Press.

Resentment. (n.d.). In Cambridge English Dictionary. https://dictionary.cambridge.org/dictionary/ english/resentment

Salmela, M., \& Capelos, T. (2021). Ressentiment: A complex emotion or an emotional mechanism of psychic defences? Politics and Governance, 9(3), 191-203.

Scheler, M. (1912). L'homme du ressentiment [The man of resentment]. Gallimard.

Spruyt, B., Keppens, G., \& Van Droogenbroeck, F. (2016). Who supports populism and what attracts people to it? Political Research Quaterly, 69(2), 335-346.

Sullivan, G. (2021). Political reactionism as affective practice: UKIP supporters and non-voters in pre-Brexit England. Politics and Governance, 9(3), 260-273.

Tavory, I., \& Timmermans, S. (2014). Abductive analysis: Theorizing qualitative research. University of Chicago Press.

Timmermans, S., \& Tavory, I. (2012). Theory construction in qualitative research from grounded theory to abductive analysis. Sociological Theory, 30(3), 167-186.

Tormey, S. (2014). The contemporary crisis of representative democracy. Democratic Theory, 1(2).

Tormey, S. (2015). The end of representative politics. Polity Press

Ure, M. (2015). Resentment/Ressentiment. Constellations, 22(4), 599-613.

Van Ingelgom, V. (2020). Focus groups: From data generation to analysis. In L. Curini \& R. J. Franzese (Eds.), SAGE handbook of research methods in political science and international relations (pp. 1190-1210). SAGE.

White, J. (2010). Europe in the political imagination. JCMS, 48(4), 1015-1038.

\section{About the Authors}

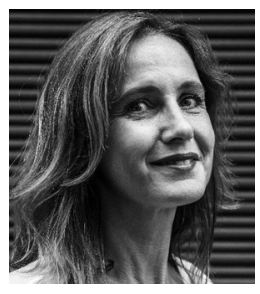

Karen Celis is Research Professor at the Department of Political Science of the Vrije Universiteit Brussel, and Co-Director of RHEA Centre of Expertise Gender, Diversity, Intersectionality. She conducts theoretical and empirical research on the democratic quality of political representation from an intersectional perspective.

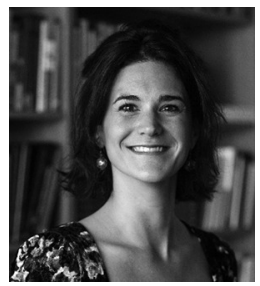

Louise Knops is a Postdoctoral Researcher affiliated to the Vrije Universiteit Brussel in political science looking at contemporary expressions of citizens' indignation in the Belgian landscape. Her research interests cover digital democracy, social movements, populism, and political representation.

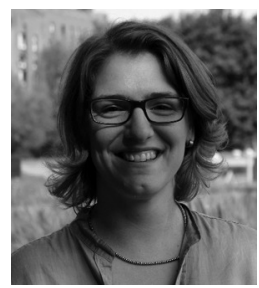

Virginie Van Ingelgom is a Research Associate Professor FRS-FNRS at the Institut de Sciences Politiques Louvain-Europe, UCLouvain. Her research interests focus on the issue of legitimacy at both the national and the European levels, on policy feedbacks and the links between democracy, neoliberalism, and supranationalization, and on the methodological issues of using qualitative comparative analysis. 


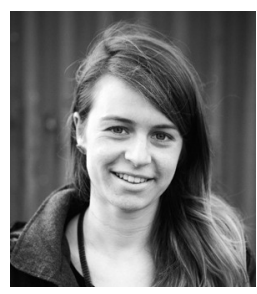

Soetkin Verhaegen is Assistant Professor in European politics at the Faculty of Arts and Social Sciences at Maastricht University, and Associated Researcher at UCLouvain and Stockholm University. Her research interests include legitimacy perceptions, multilevel governance, European identity, youth, socialization, political participation, and elites. She is specialized in survey research and focus groups. 